August 2021

\title{
China's Robotics \\ Patent Landscape
}

CSET Data Brief

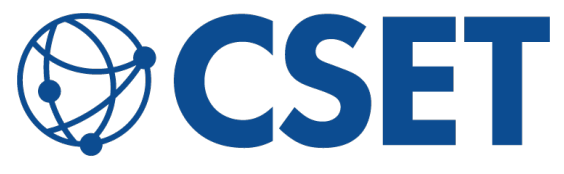

\section{AUTHOR}

Sara M. Abdulla

CENTER for SECURITY and

EMERGING TECHNOLOGY 


\section{Introduction}

This data brief explores trends in Chinese robotics patenting as a measure of robotics advancement. Patents are a key indicator of innovation-and in the case of robotics, of development and technological growth. China has garnered global attention for its domestic push in science and technology fields via government investment and planning. Robotics, as a critical area of S\&T, illustrates the potential impact of those policies, programs and funding.

China has seen prodigious growth in its robotics patents over the past decade. This growth corresponds with increases in Chinese robotics scholarly literature, the number of Chinese robotics companies, and the number of robots and robotics installations currently deployed in China. China's significant growth is relevant from a policy perspective: the development of China's robotics industry could give Chinese companies an advantage and produce significant market distortions. The rise of China's robotics industry also potentially challenges the United States' role as a technological leader and positions China to develop novel robotics technologies and buttress its military capacity. ${ }^{1}$

China's growth in robotics should be put in the context of its policy goals, including the Made in China 2025 plan, ${ }^{2}$ where China aims to garner a majority market share over its domestic robotics market to then become a world leader in robotics (among other fields, particularly in technology). Patenting activity, examined alongside other measures of innovation, provides an overall picture of the state of robotics development in China and suggests China may be on track to achieve these stated aims.

Key findings:

- The top patenters in robotics between 2010 and 2019 were the United States, China, Japan, South Korea, and Germany. China became the world leader in robotics patenting in 2015 after years of dramatic growth. Chinese organizations comprise most of the top 100 robotics patent grantees globally. 
- The top countries in robotics patenting are also leaders in output of robotics scholarly literature and robotics operational stock, meaning number of robots available to be deployed.

- Differences between country and regional patenting offices make direct comparisons difficult, but this analysis suggests that many of China's patents may face lower thresholds for quality control than other top countries' patents, tempering China's lead in robotics patents.

- Despite being the top robotics patenter, China is not the world's leader in production of robotics; Japan is. However, China is rapidly increasing its robotics production, number of robotics firms, and robotics purchasing.

\section{Global Trends/Background}

Robotics innovation is a key component of technological development, as it can build up countries' manufacturing capabilities, military industrial prowess, and make industries more efficient and able to push talent into more complex areas of work. One country-level indicator of technological advancement in robotics is patent activity, as it can demonstrate that work is being conducted, as well as country-level investment in robotics.

Patents are the formalization of intellectual property rights from a patenting agency, typically a national government, for an invention. These rights grant the inventor, or patent filer, the exclusive rights to that invention for a specific amount of time. Each national government has its own patent filing system, though there are some supranational systems that complement national ones (e.g., the European patent system grants inventors broad intellectual property rights across Europe). Individual inventors, companies, universities, or combinations of different organizations can file patent applications and receive granted patents. The "market" purpose for patents is for the inventor to garner economic gain from the invention, though there is also a purported societal benefit for making inventions public: after the patent period expires, the invention becomes available for use and expansion by other inventors. 
This brief examines patent families rather than individual patent documents. Patent families comprise all the patent documents, including the initial application form and subsequent amendments to the application, associated with a single invention. Patent families are grouped by sharing a single "priority document" (i.e., the original patent application made for the invention). Throughout this brief, "patent" is used to refer to a patent family with at least one granted patent document, unless otherwise noted.

Not all patents are created equal. More specifically, there is intercountry variance on the rigor of patent examination, the type of patents that are filed (i.e., if a patent is an invention patent or a utility model), among other factors. High-quality patents are more indicative of true innovation and economic value for an invention. For example, one potential indication of individual patent quality is if a patent is filed in multiple countries other than the country of origin. This suggests that inventors are genuinely interested in financial gain from bringing an invention to global markets. ${ }^{3}$ While the general purpose of patents is to secure the inventors' exclusive rights to bring an invention to market, other motivations for patenting are considered "nonmarket factors." One example of nonmarket factors for filing patents is when an organization uses a patent filing as a determinant for performance evaluations or promotions. 
Figure 1. Robotics Granted Patent Growth Against Overall

Patent Growth, 2011-2019

PERCENTAGE CHANGE IN PATENTS FROM PREVIOUS YEAR, 2011-2019

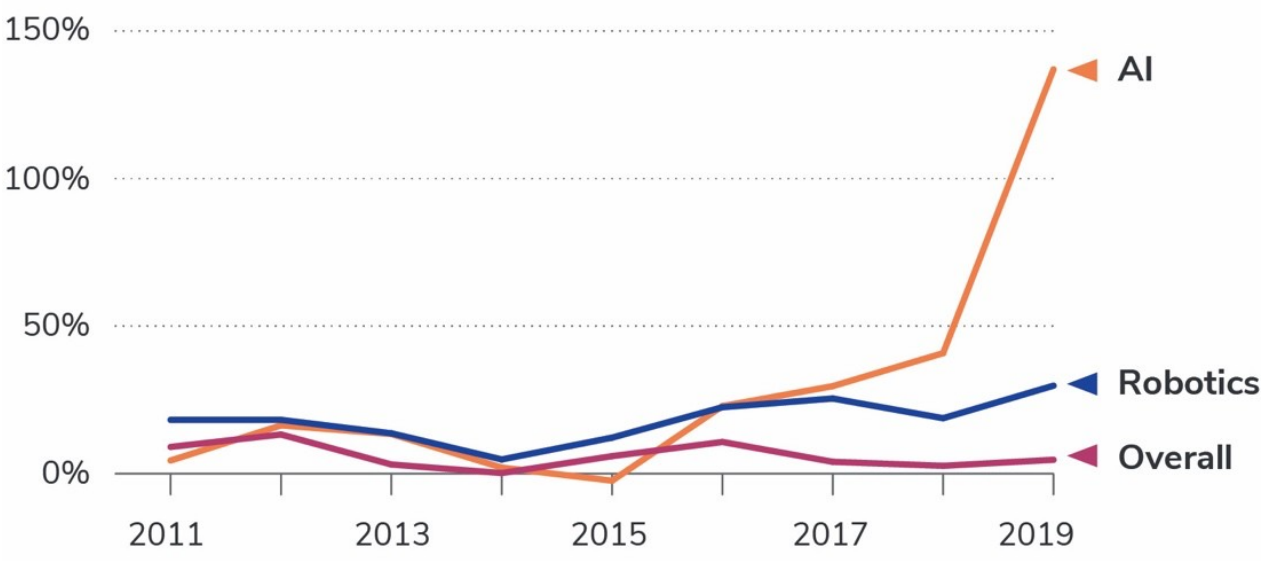

$-50 \%$

Source: 1790 Analytics patent datasets for robotics and Al patent data. ${ }^{4}$; WIPO for overall patent data. ${ }^{5}$

Granted robotics patents are growing worldwide at a faster rate than overall patents, as evident from Figure $1 .{ }^{6}$ The top five countries patenting in robotics were the United States, China, Japan, South Korea, and Germany between 2010 and 2019.* China's position as a leader in patenting in general is quite recent. ${ }^{\dagger}$ As is evident from Figure 2 below, China did not surpass the United States in number of granted robotics patents until 2009.

China became the world leader in patent applications overall (not simply in robotics patents) in $2011,{ }^{7}$ and became the world leader in granted patents in 2019. ${ }^{8}$

\footnotetext{
* See appendix for more details.

${ }^{\dagger}$ These analyses exclude utility models. Utility models (unlike the utility patents available in the United States) are like a "patent lite" in many other countries, including China, Japan, and Germany. Utility models typically have shorter pendency times, reduced scrutiny, higher grant rates, and lower threshold for novelty compared to "regular" patents. In China's case, it is also cheaper to file for a utility model; because they are more likely to be granted than an invention patent, some inventors are impelled to file both a utility patent application and an invention patent application (though only one can be granted).
} 
Figure 2. Top Countries' Robotics Patent Growth

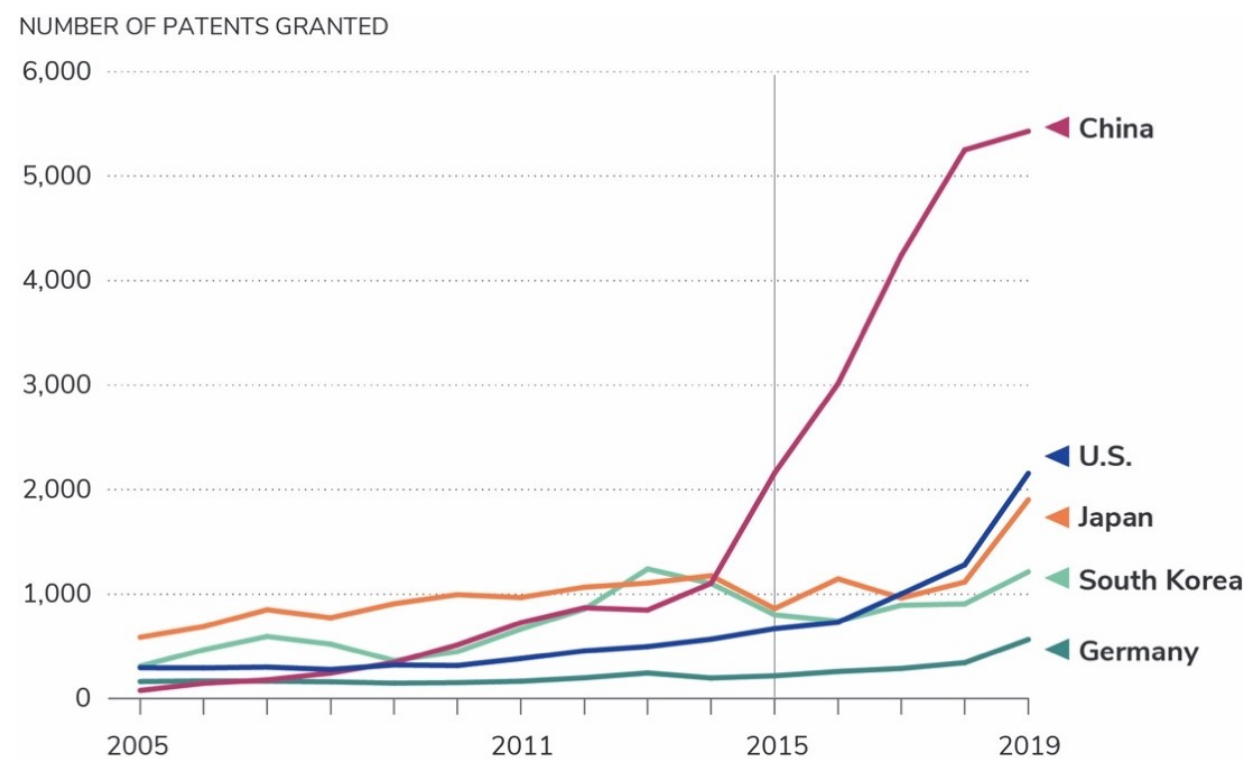

Source: 1790 Analytics robotics patent dataset.

The top three sectors for granted robotics patents in most countries include physical machine components, control systems, and industrial robotics. Worldwide, speech processing, artificial intelligence, and telepresence robotics patents have grown the fastest over 2013 through 2019. * Al patenting in itself is a field that has seen substantial growth in recent years. ${ }^{9}$ In China, speech processing, computer vision, and Al robotics patents are growing disproportionately quickly compared to other robotics sectors. Still, this rapid growth in $\mathrm{Al}$ and $\mathrm{Al}$-related fields should be considered in the context of these areas as emerging fields that had a lower number of robotics patents to begin with.

Another salient question about robotics patenting is "who is filing and receiving patents globally?" Top patent filers in different fields vary by country. Below in Figure 3, we have classified patent filers into four different categories: government funded research institutes (which can include government agencies or self-described research institutes that receive government funding), universities (which are

\footnotetext{
* Growth includes "regular" granted patents only, not granted utility models. See previous footnote and see appendix for more details.
} 
differentiated from organizations that exclusively conduct research, because their overall roles within countries are distinct), companies, and other (which includes missing data and individual inventors).

This brief distinguishes universities from other government-funded research entities because of the unique role universities play in the innovation base. ${ }^{10}$ Universities seek out international collaborators and are often thought of as fostering only basic research, which is routinely called out as open and not subjected to the restrictions or concerns of other research generators.

\section{Figure 3. Top Patent Filers in Key Robotics Countries}

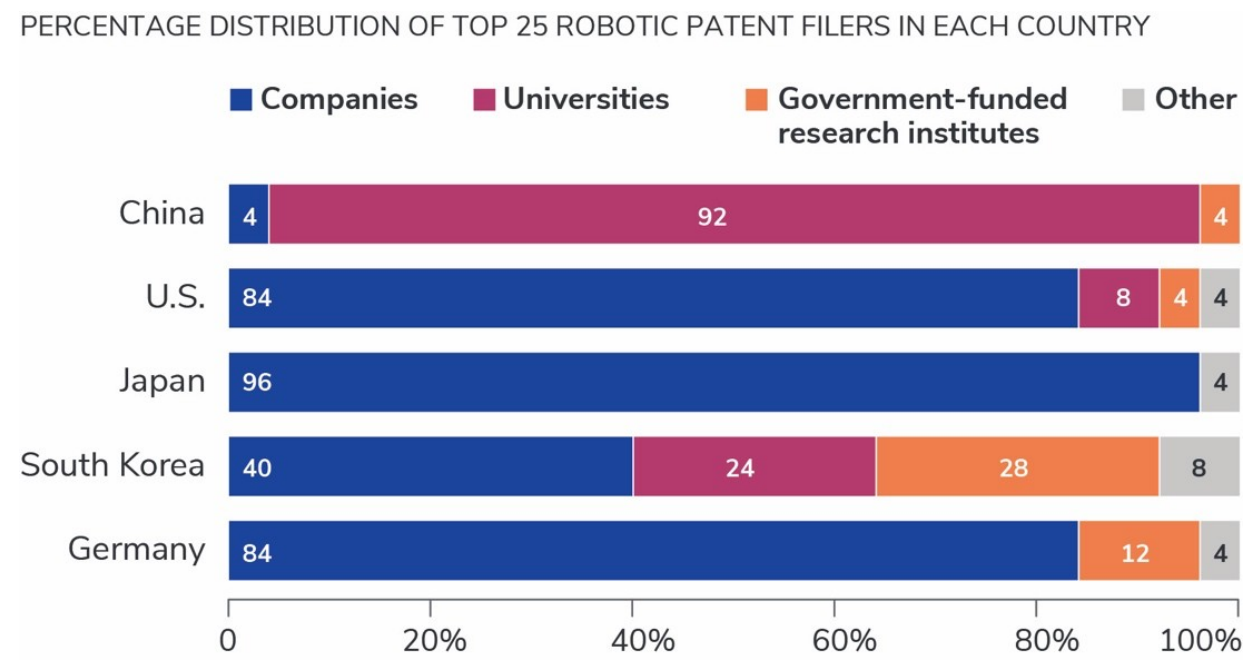

Source: 1790 Analytics robotics patent dataset, showing the distribution of top 25 robotic patent filers in each country. This brief analyzes the top 25 robotics patent filers in each country to ensure each filer had an adequate number of granted robotics patents, thus being a significant contributor within the country.

In most countries, companies, not universities, are the main sources of patent generation. However, as seen in Figure 3, China completely flips this dynamic: the vast majority of China's robotics patent filing entities are universities. Chinese companies are only a small sliver. A trailing second place for universities outputting robotics patents is South Korea, where many of the top assignees are also universities or university-affiliated. This pattern of Chinese universities as top patenters is not unique to robotics, but can also be seen in Al patents, and raises questions regarding Chinese 
universities' roles in the country's technological development. It is also possible that Chinese universities are using holding companies for robotics patents, or otherwise partnering with large companies for their research and development (R\&D). The differing role of universities in China and the United States and Europe highlights how seemingly harmless collaborations may have the potential to funnel research into China's emerging industries.

China is the most common country of origin for prolific robotics patent filers (usually companies, universities, or research institutes), with 54 percent of the top 100 patenting entities worldwide. ${ }^{11}$

Japan is second with 15 percent, followed by South Korea with 10 percent and Germany with 9 percent. This brief classifies a patent family as originating from a country if that patent was first applied for in that country. ${ }^{12}$ In Table 1 below, we have listed the top 20 most prolific robotics patents filers globally, with Chinese organizations highlighted in pink. 


\begin{tabular}{|c|c|}
\hline $\begin{array}{l}\text { COMPANIES RANKED BY NUMBER OF ROBOTICS } \\
\text { PATENTS GRANTED BETWEEN } 2005 \text { AND } 2019\end{array}$ & China \\
\hline 1. Samsung Electronics Co Ltd & South Korea \\
\hline 2. Yaskawa Electric Corp & Japan \\
\hline 3. Fanuc Corp & Japan \\
\hline 4. Lg Electronic Co Ltd & South Korea \\
\hline 5. Seiko Epson Corp & Japan \\
\hline 6. Harbin Inst Technology & China \\
\hline 7. Panasonic Corp & Japan \\
\hline 8. State Grid Corp of China & China \\
\hline 9. Univ Shanghai Jiao Tong & China \\
\hline 10. Samsung Heavy Industries Co Ltd & South Korea \\
\hline 11. Hitachi Ltd & Japan \\
\hline 12. Midea Group & Germany \\
\hline 13. Univ Tsinghua & China \\
\hline 14. Olympus Corp & Japan \\
\hline 15. Univ Zhejiang & China \\
\hline 16. Siemens Aktiengesellschaft & Germany \\
\hline 17. Hyundai Motor Co & South Korea \\
\hline 18. Univ Harbin Engineering & China \\
\hline 19. Toshiba Corp & Japan \\
\hline 20. Shenyang Inst Automation & China \\
\hline
\end{tabular}

Note: Ordered by descending number of granted robotics patents published between 2005 and 2019.

Source: 1790 Analytics robotics patent data. 
Critics have questioned the value of the patents coming out of China, given their dramatic growth in a matter of years. ${ }^{13}$ There are several indicators of quality that can be examined to gain insight on the caliber of patents coming from China, with the caveat that these metrics are crude and cannot definitively determine whether an individual patent is high-quality based on these generalized metrics. One of these quality indicators for patents is whether a patent is filed in multiple countries. Filing in multiple countries may indicate a higher quality innovation because it suggests that patent filers are concerned about protecting their innovations across multiple jurisdictions, rather than simply filing for potentially nonmarket factors (examples elucidated later in this section).

As evidenced by Figure 4 below, out of granted robotics patents that originated from China, only about 5 percent are published outside of the country. ${ }^{14}$ This value is in line with the U.S. Patent and Trademark Office's (USPTO) analysis of overall patents out of China. In contrast, approximately half of U.S. and Japanese and over one-fourth of Taiwanese originated robotics patents from 2005 to 2019 are published outside of the country. However, one should note that the market in China is enormous; it is possible that inventors opt to patent internally because they only intend to bring inventions to market or applications into practice locally. 
Figure 4. Publication Country for Robotics Patents, By Country of Origin

China 96\%

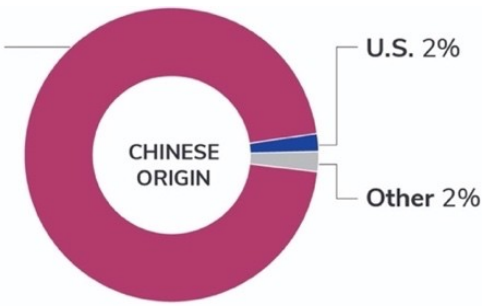

U.S. $51.2 \%$

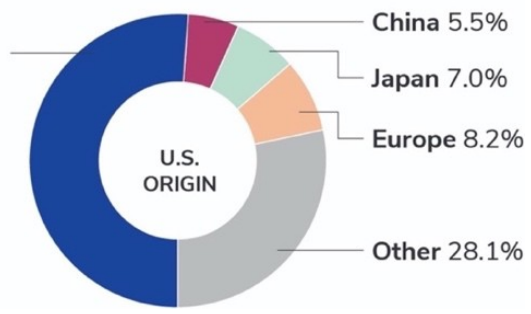

Source: 1790 Analytics robotics patent dataset.

The USPTO has also noted that it is possible that some entities have historically been motivated to file patents in China for monetary subsidies, rather than for market factors. ${ }^{15}$ Subsidies appear to be one of China's strategies to drive technological growth within the country. These strategies can be summarized as its six l's:

- Incentivize by providing government subsidies for technology installations and work.

- Invent by investing government funding into manufacturing and R\&D.

- Invite by allowing foreign technology companies to collaborate in China.

- Impose by setting up regulations to favor Chinese intellectual property over foreign intellectual property.

- Invest by facilitating the acquisition of foreign technology companies by Chinese companies.

- Infiltrate by directing intellectual property theft from foreign technology companies. ${ }^{16}$ 
The primary historic subsidies worth mentioning with respect to patenting in China are cost reimbursement subsidies that compensate inventors for filing patents. The amount inventors receive for filing a patent varies by region, as it is often regional governments that provide the monetary compensation (e.g. Beijing reportedly gave RMB 1,500 while Shanghai reportedly provided up to RMB 2,000 plus 80 percent of the cost of filing for granted invention patents). ${ }^{17}$ Inventors also receive more money for filing international patents than they do for filing domestic patents: for example, an inventor in Shanghai can receive RMB 30,000 for an international patent. However, these subsidies may be capped per filing entity (e.g., in Beijing, they are capped at RMB 1 million annually), which may have tempered the motives to file frivolously for extremely large companies, while being more of an incentive for smaller and medium-sized organizations for whom that is a more significant amount of money.

The Chinese government recently released a notice ${ }^{18}$ stating that universities should focus on improving the quality, not quantity, of their patents. They also barred the use of professors' and departments' number of patent applications in performance evaluations and using universities' numbers of patent applications as a metric in university rankings to further disincentivize frivolous patent applications. Additionally, they prohibit subsidies for patent applications and mandate that universities gradually eliminate subsidies for granted patents, except for "subsidies" that include inventors receiving a larger share of proceeds from the patents via the university patent departments. The Chinese government announced in January 2021 that it would end government subsidies for patent filings in an attempt to improve the quality composition of its patent output. ${ }^{19}$

A 2014 analysis by Fisch et al. ${ }^{20}$ of patents filed from 2000 to 2009 found that both regional cost reimbursement subsidies and government investment in top universities (i.e., research excellence subsidies, for universities that received special Chinese government funding), ${ }^{21}$ appeared to lead to increased patent applications in China. Using the number of forward citations patents from a university have in the first five years postpublication as a measure of patent quality, the authors found that 
research excellence subsidies appeared to increase the quality of patents in Chinese universities.

Cost reimbursement subsidies historically have not appeared to have a significant improvement on patent quality, though the cited analyses are based on pre-2010 data. ${ }^{22}$ Researchers have frequently questioned the effects of cost reimbursement subsidies on the quality composition of Chinese patents, contending that China's high patent output is padded with frivolous patents filed by parties seeking to capitalize on Chinese subsidies or on non-market values such as prestige in academia.

Note that despite the special subsidies that exist for Chinese inventors who file outside the country ("PCT filings"), robotics filings outside the country remain relatively low in absolute numbers and compared to the country's overall output.

Additionally, subsidies for international patents can remain until June 2025 , though they will be capped at 50 percent of official filing fees. ${ }^{23}$

Still, as the USPTO notes, there are still other non-market factors that incentivize Chinese inventors to patent their ideas, such as preferential corporate income tax rates ${ }^{24}$ and to fulfil requirements to be listed on the Shanghai Stock Exchange's Science and Innovation Board (i.e., China's version of the Nasdaq). ${ }^{25}$

Another quality indicator for patents is whether the patents are granted as "invention patents" or utility models. Utility models have a lower threshold for innovation in examination by patent agencies and are cheaper to file, and on a mass scale may be less likely to be high-profile inventions. For example, an analysis for Bloomberg found that the majority of Chinese utility models granted in 2013 were abandoned within five years. ${ }^{26}$ Still, one should note that this quality indicator is particularly conditional, because there are several reasons an inventor may opt to file for a utility model instead of a regular patent that does not include the quality of the innovation. Unlike other countries' top robotics patent filing organizations, most of the Chinese organizations that file robotics patents have a significantly lower proportion of invention patents than the top international robotics filers; more of their "granted 
patents" are the less prestigious utility models. Thus, if one was to only examine overall granted patents excluding utility models, Chinese organizations often appear less prolific than they actually are, ${ }^{27}$ indicating the possibility that robotics development in China is occurring far slower than raw patents numbers suggest. However, even when examining only "regular" granted patents, as evident from the previous section, China currently outperforms all other countries in robotics patenting.

We examined China's universities by the percentage of their patents that are nonutility models. A high rate of granted "regular" (i.e., invention) patents would suggest that the schools are not only engaging in significant robotics work, but also that they are filing more serious patents. This indicates that universities are seeking intellectual property protection for economic gain rather than simply seeking government subsidies or other nonmarket motivators. This, again, highlights the different role universities play in China's intellectual property system. ${ }^{28}$ Below in Table 2, are China's top 20 patenting entities by the percentage of their robotics patents that are nonutility models. 
Table 2. Top Chinese Robotics Patenting Entities, 2005-201929

Entities ordered by number of regular patents granted between 2005 and 2019
UNIVERSITY TYPE

- Double First-Class
- Seven Sons of National Defense

- Top 10 feeder into major Chinese defense companies

NUMBER OF PATENTS

\begin{tabular}{|c|c|c|c|}
\hline Regular & Utility & Total & $\%$ Regular \\
\hline 546 & 82 & 628 & $87 \%$ \\
\hline 436 & 1092 & 1528 & 29 \\
\hline 430 & 42 & 472 & 91 \\
\hline 380 & 107 & 487 & 78 \\
\hline 333 & 203 & 536 & 62 \\
\hline 293 & 135 & 428 & 68 \\
\hline 282 & 324 & 606 & 47 \\
\hline 277 & 155 & 432 & 64 \\
\hline 249 & 24 & 273 & 91 \\
\hline 229 & 53 & 282 & 81 \\
\hline 216 & 58 & 274 & 79 \\
\hline 216 & 32 & 248 & 87 \\
\hline 213 & 64 & 277 & 77 \\
\hline 207 & 63 & 270 & 77 \\
\hline 170 & 399 & 569 & 30 \\
\hline 165 & 76 & 241 & 68 \\
\hline 157 & 55 & 212 & 74 \\
\hline 157 & 97 & 254 & 62 \\
\hline 135 & 214 & 349 & 39 \\
\hline 133 & 88 & 221 & 60 \\
\hline
\end{tabular}

Source: 1790 Analytics robotics patent dataset.

Four of the "Seven Sons of National Defense" of Chinese universities, or universities with historical ties to the Chinese military, are featured on the list of most prolific Chinese patenters. Additionally, two other universities are also in the top 10 feeder schools into major Chinese military defense companies. ${ }^{30}$ These universities are largely featured in the high-quality class. The majority of the remainder of the high-quality patenting organizations are double first-class universities, which are universities that receive preferential treatment from the Chinese 
Ministries of Education and Finance for their potential to be "worldclass" universities. One notable exception in this list of mostly universities is Hon Hai Precision Industry, an organization with a high proportion of invention patents, also known as Taiwan-based Foxconn that has offices in China.

Only time will tell if the number of granted "regular" patents in China will decrease as a result of decreased subsidies, though there is reason to believe that for high-quality, high-quantity Chinese assignees, granted robotics patents are indeed reflective of significant robotics research/work.

\section{Robotics Research Output}

In addition to robotics patents, this brief also examines trends in scholarly research publications related to robotics. The top five robotics patenting countries make it into the top six countries for robotics scholarly output, with the United Kingdom as the 5th and South Korea as the 6th most prolific robotics paper producers. Additionally, it is particularly notable to see South Korea in the top 10 of robotics research when the country is not in the top 10 of overall scientific scholarly articles.

\section{Table 3. Top 10 Countries by Robotics Paper Output, 2010-2019} NUMBER OF ROBOTICS PAPERS

\begin{tabular}{ll} 
1. China & 53,219 \\
\hline 2. U.S. & 43,146 \\
\hline 3. Japan & 21,274 \\
\hline 4. Germany & 14,666 \\
\hline 5. United Kingdom & 10,148 \\
\hline 6. South Korea & 9,652 \\
\hline 7. Italy & 9,440 \\
\hline 8. France & 8,195 \\
\hline 9. Canada & 7,330 \\
\hline 10. Spain & 5,988
\end{tabular}

Source: Data from English-language academic journals and conference papers in the Web of Science, China National Knowledge Infrastructure (CNKI), Dimensions, Microsoft Academic Graph (MAG), and arXiv from 2010-2019. ${ }^{31}$ 
Japan, Germany, and South Korea, are leaders in robotics scholarly output, despite not usually making it as high on world scholarship output rankings. Of these countries, only South Korea and Japan have 1 percent or more of their overall scholarly output classified as robotics papers, suggesting they have a more concentrated focus on robotics than the other top producers of robotics scholarly output. Their leadership in robotics scholarly output is consistent with their leadership in robotics patenting and in robotics operational stock (more on this subject in the next section), and is supporting evidence that countries with high robotics patents output are pursuing advances in robotics technologies.

Furthermore, the top Chinese universities in robotics patenting are also China's leaders in robotics papers: the Chinese Academy of Sciences, Harbin Institute of Technology, Beihang University, Shanghai Jiao Tong University, Beijing Institute of Technology, Tsinghua University, Northwestern Polytechnical University, top the lists. This overlap supports the possibility that Chinese universities use patents as a form of academic output.

\section{Chinese Industrial Robotics}

While China is one of the leaders in robotics patents and robotics scholarly output, Japan is the world's top robot manufacturer. ${ }^{32}$ Still, it is worth examining the growth in China's robotics industry over the same period that robotics patents were examined, to assess if there appear to be parallel growth patterns and to gain a more comprehensive view of China's robotics landscape. This brief examines top countries' operational stock of industrial robots and robot installations, using data from the International Federation of Robotics (IFR). ${ }^{33}$ 
Figure 5. Operational Stock of Leading Robotics Patenting Countries

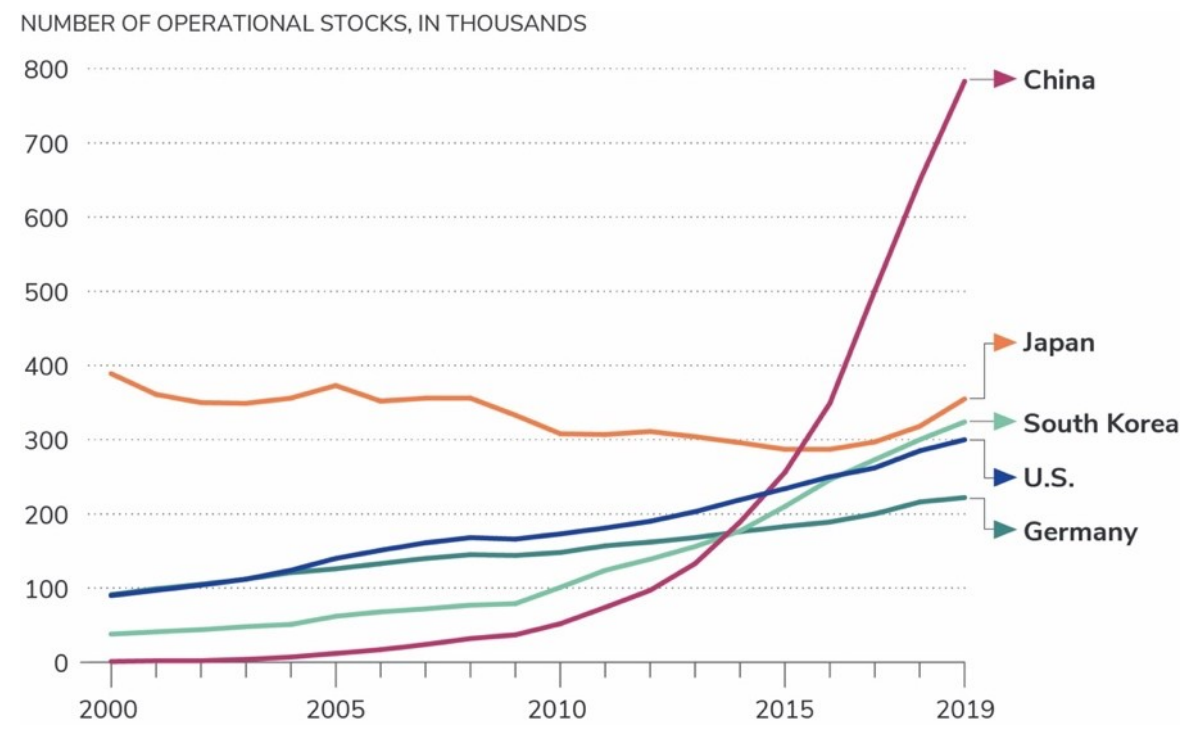

Source: International Federation of Robotics Industrial Robots Report 2020.

As evident from Figure 5, robotics operational stock growth rates in China began to surge in 2014. When considering its massive population, China actually trails behind developed countries in rankings in robot to working-age population ratios. That is, the number of robots in comparison to China's population is not terribly high compared to European countries, the United States, and economically developed East Asian countries such as Taiwan and Singapore, though China still ranks above the global average for robot adoption to population ratio. ${ }^{34}$ Furthermore, China adopted robotics on a large scale incredibly rapidly. China accomplished its goal of achieving 150 robots per ten thousand employees by 2018 , with around 187 robots per ten thousand employees in 2019 and up from 36 robots per ten thousand employees in 2014. IFR also notes that the business outlook for China is positive, as China steadily increases its robot exports, ${ }^{35}$ particularly to South Asia and Eastern Europe. ${ }^{36}$ 
Figure 6. Dramatic Market Growth for Robotics in China

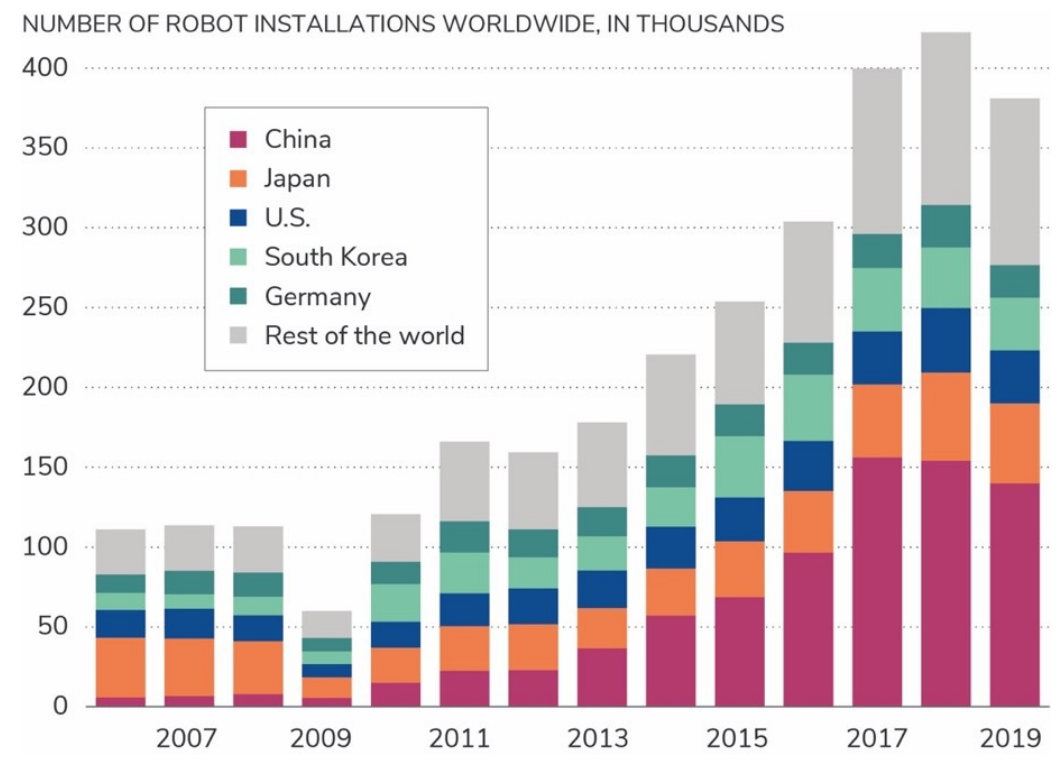

SHARE OF ROBOT INSTALLATIONS WORLDWIDE (\%)

\begin{tabular}{|c|c|c|c|c|c|c|}
\hline & China & & Japan & & South Korea & Germany \\
\hline 2006 & 5 & 34 & & 16 & 10 & 10 \\
\hline 2007 & 6 & 32 & & 16 & 8 & 13 \\
\hline 2008 & 7 & 29 & & 14 & 10 & 13 \\
\hline 2009 & 9 & 21 & & 14 & 13 & 14 \\
\hline 2010 & 12 & 18 & & 14 & 19 & 12 \\
\hline 2011 & 14 & 17 & & 12 & 15 & 12 \\
\hline 2012 & 14 & 18 & & 14 & 12 & 11 \\
\hline 2013 & 21 & 14 & & 13 & 12 & 10 \\
\hline 2014 & 26 & 13 & & 12 & 11 & 9 \\
\hline 2015 & 27 & 14 & & 11 & 15 & 8 \\
\hline 2016 & 32 & 13 & & 10 & 14 & 7 \\
\hline 2017 & 39 & 11 & & 8 & 10 & 5 \\
\hline 2018 & 36 & 13 & & 10 & 9 & 6 \\
\hline 2019 & 37 & 13 & & 9 & 9 & 5 \\
\hline
\end{tabular}

Source: International Federation of Robotics data.

In recent years, China has become the biggest market for industrial robots, as illustrated by Figure 6 above. China overtook Japan as the world's largest robotics market in 2013. While China continues to import most of its reported robot installations and operational stock, China's internal market share is increasing. In 2019, about 29 percent of its robotics units were provided by Chinese suppliers, ${ }^{37}$ up from 26 percent in $2018^{38}$ and from 25 percent 2017. ${ }^{39}$ These increases may be attributed to the Made in China 2025 plan released in 2015, where the Chinese government 
intends to propel the country towards self-sufficiency and away from foreign imports, particularly in emerging areas of technology like clean energy and robotics. ${ }^{40}$ Additionally, the Chinese electronic robots industry is fairly strong and is responsible for 51 percent of the global electronics installations; Chinese producers are also responsible for the majority of its domestic metals and machineries, as well as plastics and chemical industries. ${ }^{41}$

Some of China's leading companies developing robots include Honyen (welding robots), Siasun (human-robot interactors), which is affiliated with the Chinese Academy of Sciences, and Bochi Machine Tool Group. ${ }^{42}$ These companies' robots are purportedly on par with Japan's in terms of quality, but are considerably cheaper. Much of these companies' success is associated with their automation, which is expected to become more dramatic with the COVID-19 pandemic's associated shutdowns and layoffs, in addition to their aging workforce. Additionally, the Chinese government appears to be subsidizing robotics startups as part of their trek towards technological self-sufficiency. ${ }^{43}$ The Chinese government reportedly subsidizes foreign acquisitions of robotics firms by Chinese companies as part of its national strategy towards robotics leadership. ${ }^{44}$

Though patent filings may not be directly and immediately resulting in global dominance in robot production, the dramatic increase in robotic production in the past decade suggests that there could simply be a temporal lag between research, patent filing, and commercialization. Additionally, while the bulk of China's robotics patents are filed by state firms and universities, the number of registered robotics firms is rapidly increasing, from around two hundred in 2005 to over six thousand in 2015. Much of the growth of these firms appears to be linked to government subsidies. Furthermore, even though these firms are small, their growth could be contributing to the rise of patents as well. ${ }^{45}$

Again, China's journey towards self-sufficiency could also partially explain its particularly low rates of international filing in robotics patents: in addition to the fact that China's commercial goods market is enormous, it is also the world's largest robotics market. Harkening back to Foxconn's role as a high-quality, high-quantity patenter in China, the extent of Foxconn's output in China is 
unclear, as it is not included in the IFR data below, but some reports state Foxconn has fifty thousand robots in China and can produce ten thousand per year. ${ }^{46}$ Indeed, some analysts note that part of China's strategy is to garner internal market share by edging out international competitors with cheaper products, before using that internal dominance to gain international market share with low-cost, sufficient-quality products. From there, China can leverage the advantages of market dominance to make true innovative strides in technology. One shining example of this longgame strategy is Huawei's humble beginnings as a cheap telecommunications alternative to more expensive products in China to now being a leader in telecommunications and the foreman for $5 \mathrm{G} .{ }^{47}$

The bulk of China's robotics operational stock is in manufacturing, distantly followed by education/research/development. Again, their buy ups of manufacturing robots may be associated with their progress towards automation and towards their goal in becoming a leader in technological production.

\section{Conclusion}

- China has seen rapid growth in robotics patenting and domestic robotics stock in the past decade, consistent with its policy goals to erode its reliance on foreign robots in its internal market.

- The top robotics patent filing entities in China are universities, unlike other top countries with high numbers of robotics patents, where companies are top patent filing entities. This inconsistency raises questions about the role of Chinese universities in China's technological development, including whether these patents from universities translate to applications, whether these patents are used by universities' internal holding companies, and whether universities are partnering with larger companies to develop these patents and potential corresponding applications and capabilities.

- Chinese subsidies have historically appeared to play a significant role in the steep rise in robotics patents, as well 
as patents in general. China announced an end to most government patent subsidies in January 2021.

- It remains to be seen whether the end of government subsidies will temper the growth of Chinese robotics patents or whether it will improve the quality composition of Chinese robotics patents. Regardless, other indicators of robotics progress, such as scholarly output and robot purchases, suggest that China is trending towards robotics world leadership.

- The top countries in robotics patenting were also the top countries in robotics scholarly literature.

- While China is not a leader in robotics production, they are the world's largest market for purchasing robots. Besides China, the top countries in robotics patenting are the top countries in active robotics operational stocks. 
Author

Sara M. Abdulla is a data research analyst at CSET.

Acknowledgments

For review, feedback, and general support, the author would like to thank Autumn Toney, Dewey Murdick, Igor Mikolic-Torreira, Rebecca Gelles, Melissa Flagg, Margarita Konaev, Emily Weinstein, Diana Gelhaus, Anna Puglisi, Catherine Aiken, Shelton Fitch, Matt Mahoney, Jonas Nahm, Patrick Thomas and Anthony Breitzman. Additional thanks to Farhana Hossein for data visualization support. All errors are the author's own.

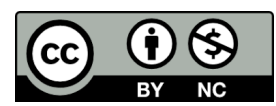

(c) 2021 by the Center for Security and Emerging Technology. This work is licensed under a Creative Commons Attribution-Non Commercial 4.0 International License.

To view a copy of this license, visit https://creativecommons.org/licenses/by-nc/4.0/. 


\section{Appendix}

The ordered countries for robotics patents granted between 2010 and 2019 are as follows:

Figure A1. Top 20 Countries and Patenting Agencies by Granted Robotics Patents, 2010-2019

\begin{tabular}{l|l|}
\hline 1. China & NUMBER OF ROBOTICS PATENTS GRANTED \\
\hline 2. Japan & 25,154 \\
\hline 3. South Korea & 15,130 \\
\hline 4. U.S. & 11,144 \\
\hline 5. Germany & 9,554 \\
\hline 6. Russia & 3,439 \\
\hline 7. France & 1,701 \\
\hline 8. European Patent Office & 1,129 \\
\hline 9. Taiwan & 942 \\
\hline 10. Italy & 883 \\
\hline 11. United Kingdom & $385 \mid$ \\
\hline 12. Spain & $376 \mid$ \\
\hline 13. Sweden & $364 \mid$ \\
\hline 14. Netherlands & $307 \mid$ \\
\hline 15. Canada & $274 \mid$ \\
\hline 16. Austria & $213 \mid$ \\
\hline 17. Australia & $192 \mid$ \\
\hline 18. Poland & $154 \mid$ \\
\hline 19. Switzerland & $147 \mid$ \\
\hline 20. Mexico & $113 \mid$ \\
\hline
\end{tabular}

Figure A.1: Data from 1790 Analytics. 
Global growth of robotics patent by functions and applications:

Figure A2. Growth of Granted Robotics Patents by Functions and Applications

\begin{tabular}{|c|c|c|c|c|}
\hline \multirow{3}{*}{ ROBOT FEATURE } & \multicolumn{4}{|c|}{ MEAN YEARLY GROWTH (\%) } \\
\hline & \multicolumn{2}{|c|}{ FROM 2006 TO 2019} & \multicolumn{2}{|c|}{ FROM 2013 TO 2019} \\
\hline & World $\longrightarrow$ & China & World & China \\
\hline Aerospace & 22 & 41 & 25 & 67 \\
\hline Agriculture & 20 & 34 & 23 & 35 \\
\hline Consumer & 22 & 47 & $24 \square$ & 52 \\
\hline Education & 24 & 34 & 14 & 36 \\
\hline Entertainment & 16 & 33 & 8 & 29 \\
\hline Humanoid Exoskeleton & 42 & 76 & $27 \square$ & 49 \\
\hline Industrial & $13=$ & 37 & 16 & 42 \\
\hline Medical & 23 & 51 & 20 & 30 \\
\hline Military Security & $16 \square$ & 38 & 20 & 64 \\
\hline Telepresence & 25 & 58 & 29 & 67 \\
\hline Transportation & 18 & 80 & 15 & 32 \\
\hline Underwater & 39 & 36 & 25 & 46 \\
\hline Artificial Intelligence & 33 & 41 & 34 & 57 \\
\hline Physical Components & 15 & 40 & 14 & 39 \\
\hline Control Systems & 19 맘 & 44 & 18 & 42 \\
\hline Sensors Measurement & 19 & 43 & 16 & 36 \\
\hline Speech & 39 ra & 66 & 45 & E 163 \\
\hline Vision & 23 & 83 & 26 & 70 \\
\hline
\end{tabular}

Figure A2: Data from 1790 Analytics. Note that types are not exclusive: e.g., a single patent could be classified as both "artificial intelligence" and "vision." Granted patents only. 


\section{Endnotes}

1 "China's Industrial and Military Robotics Development," prepared by Defense Group Inc. (DGI). October 2016.

https://www.uscc.gov/sites/default/files/Research/DGl_China\%27s\%20Industrial \%20and\%20Military\%20Robotics\%20Development.pdf

2 "Made in China 2025: Global Ambitions Built on Local Protections." United States Chamber of Commerce. 2017.

https://www.uschamber.com/sites/default/files/final_made_in_china_2025_repor t_full.pdf

3 "Trademarks and patents in China: The impact of non-market factors on filing trends and IP systems." January 2021.

https://www.uspto.gov/sites/default/files/documents/USPTOTrademarkPatentsInChina.pdf

${ }^{4}$ Unless otherwise noted, patent family data is from 1790 Analytics, who used IEEE standards and applications to buckets patent documents globally into Al and robotics groupings. We determined the year of patent granting by extracting the latest "publication date" from each patent family that contained at least one granted patent. There are multiple methods of extracting the dates by patent family, including extracting the first date of filing (i.e., application date) and first publication date.

${ }^{5}$ WIPO data are for patent documents, not families. Examining percentage growth avoids issues that come with measuring different patenting units.

${ }^{6}$ Percentage growth is calculated by subtracting the previous year's data from the current year's data, dividing that value by the previous year's data, and multiplying that result by 100 to get it into percent. E.g., https://pages.uoregon.edu/rgp/PPPM613/class8a.htm

7 “Global IP Filings Continue to Grow, China Tops Global Patent Filings." WIPO. December 11, 2012.

https://www.wipo.int/pressroom/en/articles/2012/article_0025.htm|\#: :text=In\% 202011\%2C\%20China\%20received\%20526\%2C412,for\%2072\%25\%20of\%2 0this\%20increase.

8 "In a first, China knocks U.S. from top spot in global patent race." Reuters. April 7, 2020. https://www.reuters.com/article/us-usa-china-patents/in-a-first-chinaknocks-u-s-from-top-spot-in-global-patent-race-idUSKBN21P1P9

${ }^{9}$ Dewey Murdick and Patrick Thomas, "Patents and Artificial Intelligence: A Primer," (Center for Security and Emerging Technology, September 2020). https://doi.org/10.51593/20200038 
${ }^{10}$ Johnson et al, "The China question: Managing risks and maximising benefits from partnership in higher education and research. (M-RCBG Associate Working Paper Series | No. 161, March 2021).

https://www.hks.harvard.edu/sites/default/files/centers/mrcbg/files/AWP_161_fi $\underline{\text { nal.pdf }}$

${ }^{11}$ We examined the top 100 patenting entities here because they have a much larger sample size than any of the individual countries' top 100 patenting entities. Therefore, there was less of a worry of lower-ranking (e.g., 99th) global patenting entities having too few granted robotics patents to be worth examining.

${ }^{12}$ This method (called using the "priority country") is not perfect, but is a widelyused solution to the problem of allocating patents to countries, especially where inventor location and organizational location are different. CSET researchers ran a test comparing the priority country to the filing country of the assignee (i.e. the organization or individual inventor that filed the patent), and the country of the "first inventor", and reported a high level agreement between the three approaches. See p.20 of Dewey Murdick and Patrick Thomas, "Patents and Artificial Intelligence: A Primer," (Center for Security and Emerging Technology, September 2020). https://doi.org/10.51593/20200038. Note that, if the first patent application is a PCT application, then the priority country is derived from the country code on the PCT application.

${ }^{13}$ Lulu Yilun Chen, "China Claims More Patents Than Any Country-Most Are Worthless.” Bloomberg. October 032018.

https://www.bloombergquint.com/technology/china-claims-more-patents-thanany-country-most-are-worthless

${ }^{14}$ This value includes patents that are published only outside of China and those that are published both in and outside of China.

15 "Trademarks and patents in China: The impact of non-market factors on filing trends and IP systems." USPTO. January 2021. https://www.uspto.gov/sites/default/files/documents/USPTOTrademarkPatentsInChina.pdf

${ }^{16}$ Belton et al. 2020. https://manufacturingpolicy.indiana.edu/doc/made-inchina-2020.pdf

${ }^{17}$ http://afdip.com/index.php?ac=article\&at=read\&did=2557

${ }^{18}$ Original CSET Translation of "Certain Opinions of the Ministry of Education, the China National Intellectual Property Administration, and the Ministry of Science and Technology on Improving the Quality of Patents at Institutes of Higher Education and Promoting [Patent] Conversion and Use" 
[教育部 国家知识产权局 科技部 关于提升高等学校专利质量 促进转化运用的若干 意见], The Ministry of Education (教育部), the China National Intellectual Property Administration (国家知识产权局), and the Ministry of Science and Technology (MOST; 科技部), February 3, 2021.

19 Original CSET Translation of "Notice of the China National Intellectual Property Administration on More Strictly Regulating Patent Applications" [国家知识产权局 关于进一步严格规范专利申请行为的通知], China National Intellectual Property Administration (国家知识产权局), January 27, 2021.

${ }^{20}$ Fisch, Christian \& Block, Joern \& Sandner, Philipp. (2014). Chinese university patents: quantity, quality, and the role of subsidy programs. The Journal of Technology Transfer. 41. 1-25. 10.1007/s10961-014-9383-6. Accessed from https://www.researchgate.net/publication/284833645_Chinese_university_pate nts_quantity_quality_and_the_role_of_subsidy_programs.

${ }^{21}$ Project 985-funded universities. See Fisch et al. 2014 for more details, or Xiaohua Zong \& Wei Zhang (2019) "Establishing world-class universities in China: deploying a quasi-experimental design to evaluate the net effects of Project 985," Studies in Higher Education, 44:3, 417-431, DOI:

10.1080/03075079.2017.1368475 from https://www.tandfonline.com/doi/abs/10.1080/03075079.2017.1368475?journ alCode $=$ cshe20.

${ }^{22}$ Xibao Li, "Behind the recent surge of Chinese patenting: An institutional view," Research Policy, Volume 41, Issue 1, 2012, Pages 236-249, ISSN 0048-7333, https://doi.org/10.1016/j.respol.2011.07.003.

(https://www.sciencedirect.com/science/article/pii/S0048733311001302)

${ }^{23}$ Original CSET Translation of "Notice of the China National Intellectual Property Administration on More Strictly Regulating Patent Applications"

China National Intellectual Property Administration (国家知识产权局). The Noticeis dated January 27, 2021 and was posted to the website the following day, January 28, 2021.https://cset.georgetown.edu/publication/notice-of-the-china- nationalintellectual-property-administration-on-more-strictly-regulating- patentapplications/

${ }^{24}$ https://www.pwccn.com/en/services/tax/china-rd-incentive-service/high-andnew-technology-enterprise.html

25 "Patents Required to List on the Shanghai Stock Exchange's Science \& Technology Board." China IP Law Update. March 20, 2020. https://www.chinaiplawupdate.com/2020/03/patents-required-to-list-on-theshanghai-stock-exchanges-science-technology-board/. See also https://www.bbc.com/news/business-53509651

${ }^{26}$ Lulu Yilun Chen, "China Claims More Patents Than Any Country-Most Are Worthless.” Bloomberg. October 032018. 
https://www.bloombergquint.com/technology/china-claims-more-patents-thanany-country-most-are-worthless

${ }^{27}$ One should note the caveat that some serious patents are utility models and that this metric is still a crude one. Other research analyses have also investigated the proportion of utility models compared to invention patents as an indicator of quality. E.g., https://research.stlouisfed.org/publications/economicsynopses/2018/05/04/what-does-chinas-rise-in-patents-mean-a-look-atquality-vs-quantity/

${ }^{28}$ Prud'homme, Dan (2012): A statistical analysis of China's patent quality situation and larger innovation ecosystem. Published in: European Union Chamber of Commerce in China Publications (August 2012): pp. 39-61. https://mpra.ub.uni-muenchen.de/51619/

${ }^{29}$ Organization names clarified from original names in the 1790 Analytics dataset here for the reader's ease.

${ }^{30}$ Ryan Fedasiuk and Emily Weinstein, "Universities and the Chinese Defense Technology Workforce," (Center for Security and Emerging Technology, December 2020). https://doi.org/10.51593/20200043

${ }^{31}$ Robotics scholarly papers with at least 1 author affiliated from a country in question. Based on English-language papers only and using CSET's arXiv paper classifier that uses machine learning methods to classify robotics papers. For more details, see James Dunham, Jennifer Melot, and Dewey Murdick, "Identifying the Development and Application of Artificial Intelligence in Scientific Text," arXiv, May 28, 2020, https://arxiv.org/abs/2002.07143.

${ }^{32}$ IFR (International Federation of Robotics). (2020). World robotics 2020. Industrial robots.p.206. International Federation of Robotics, Frankfurt am Main. Retrieved from http://www.worldrobotics.org

${ }^{33}$ IFR (International Federation of Robotics). (2019). World robotics 2019. Industrial robots.p.22. International Federation of Robotics, Frankfurt am Main. Retrieved from http://www.worldrobotics.org

${ }^{34}$ Robert D. Atkinson. "Robotics and the Future of Production and Work." October 15, 2019. ITIF. https://itif.org/publications/2019/10/15/roboticsand-future-production-and-work

${ }^{35}$ IFR (International Federation of Robotics). (2020). World robotics 2020. Industrial robots. International Federation of Robotics, Frankfurt am Main. Retrieved from http://www.worldrobotics.org

${ }^{36}$ Additionally, if one considers wages when assessing the "expected robot adoption rate" for various countries, then China is doing better in the tangible robotics realm than appears at first glance. For example, in a country like the United States or in many European countries where average wages are fairly 
high, one might expect higher robot adoption rates to displace human labor, because robots are likely to be cheaper in the longer run than paying high wages to people. On the other hand, in countries such as India or in Southeast Asia, where wages are comparably low, one would expect lower adoption rates because human labor is inexpensive and thus, organizations do not save money by not paying wages while having to pay for robot installations and robot upkeep. The Information Technology and Innovation Foundation (ITIF) calculated "expected robot adoption rates" for countries relative to their true adoption rates. ITIF found that Korea had over a 200 percent higher-than-expected adoption rate, with other East Asian countries following and China coming fourth worldwide with a 150 percent-plus higher-than-expected adoption rate using 2017 data. The United States, using 2017 data, has a 49 percent lower-thanexpected domestic robot adoption rate. China's expected-to-actual adoption ratio and ranking may be higher using 2019 data, considering their rapid increases in robot production and robot installations in the past several years. Thus, China is positioning itself to become a world leader in producing robots. Still, country robot adoption rates should also be considered in the context of available workforce population and cultural attitudes. China's workforce population is decreasing both in absolute numbers and as a share of its total population. Additionally, there is evidence that people living in East Asian countries have more favorable attitudes toward robots than people in the United States, which may be a contributing factor to higher adoption rates than "expected" based exclusively on wages.

${ }^{37}$ IFR (International Federation of Robotics). (2020). World robotics 2020. Industrial robots. International Federation of Robotics, Frankfurt am Main. Retrieved from http://www.worldrobotics.org

${ }^{38}$ IFR (International Federation of Robotics). (2019). World robotics 2020. Industrial robots. International Federation of Robotics, Frankfurt am Main. Retrieved from http://www.worldrobotics.org

${ }^{39}$ IFR (International Federation of Robotics). (2018). World robotics 2020. Industrial robots. International Federation of Robotics, Frankfurt am Main. Retrieved from http://www.worldrobotics.org

40 'Made in China 2025' plan issued. The State Council of China. May 19, 2015. http://english.www.gov.cn/policies/latest_releases/2015/05/19/content_281475 110703534.htm 
${ }^{41}$ IFR (International Federation of Robotics). (2020). World robotics 2020. Industrial robots. International Federation of Robotics, Frankfurt am Main. Retrieved from http://www.worldrobotics.org

${ }^{42}$ https://asia.nikkei.com/Business/China-tech/China-s-tech-spending-surgesas-it-strives-to-be-robotics-superpower

43 "CHINA MANUFACTURING 2025: Putting Industrial Policy Ahead of Market Forces." European Union Chamber of Commerce in China. 2017. http://docs.dpaq.de/12007-european_chamber_cm2025-en.pdf

${ }^{44}$ One example of this is when China's Midea Group acquired the German-based KUKA. Chinese acquisitions of foreign established technology companies falls into the "invest" category of their strategy towards technological advancement.

a. Belton et al. 2020. https://manufacturingpolicy.indiana.edu/doc/made-inchina-2020.pdf

b. China's Midea receives U.S. green light for Kuka takeover. Reuters. December 30 2016. https://www.reuters.com/article/us-kuka-m-amideamidea-group/chinas-midea-receives-u-s-green-light-for-kukatakeover-idUSKBN14JOSP

${ }^{45} \mathrm{H}$. Cheng, R. Jia, D. Li, H. Li. The rise of robots in China. Journal of Economic Perspectives, 33 (2) (2019), pp. 71-88

${ }^{46}$ IFR (International Federation of Robotics). (2020). World robotics 2020. Industrial robots. International Federation of Robotics, Frankfurt am Main. Retrieved from http://www.worldrobotics.org

${ }^{47}$ The Huawei Moment (forthcoming). Alex Rubin, Alan Omar Loera Martinez, Jake Dow, and Anna Puglisi. Center for Security and Emerging Technology. 